\title{
Efficiency Comparison of Grid Side Converters for DC Distribution Systems
}

\author{
M. C. Di Piazza, G. Vitale \\ Consiglio Nazionale delle Ricerche, CNR - ISSIA UOS Palermo \\ Via Dante, 1290141 Palermo Phone +39 0916113513 Fax +39 0916113028 , \\ dipiazza@pa.issia.cnr.it; vitale@pa.issia.cnr.it
}

\begin{abstract}
This paper aims to study the energy losses in Grid Side Converters (GSCs) used for grid connection of DC residential distribution systems, including renewables and storage. Two different electrical architectures have been considered, the former using an H-bridge as GSC and the latter a PFC active rectifier in association with a storage system. An observation time of one year has been fixed. The analysis is based on the same amount of energy generated by renewables and load demand, in both cases. A detailed formulation of the power losses in each component of the power converter is given. A comparison of the energy lost yearly in both the GSCs is presented, considering different sizing of the storage system.
\end{abstract}

\section{Keywords}

DC distribution system, H-bridge active rectifier, PFC active rectifier, Energy efficiency, Residential application.

\section{Introduction}

Recently, the high depth of penetration of distributed energy resources, especially in terms of building integrated photovoltaic (BIPV) plants and micro-wind turbines for domestic applications, has intensified the demand for single-phase power converters used as grid interfaces, i.e., the grid side converters (GSC) [1]-[6].

In addition, it has been highlighted that an optimisation of energy efficiency, in the field of building applications, can be achieved if suitable architectures for power distribution are chosen, for example using DC distribution schemes [7]-[8].

The GSCs, besides providing power conditioning and power flow management, should guarantee an appropriate interaction with the utility. In particular, these systems have to maintain the power quality and the stability of the grid. The international standards allow strict limits for the current total harmonic distortion (THD) factor, which can be met using converters with a reduced harmonic production, but also controlled in order to provide rejection capability respect to grid background distortion. Among the possible grid interfaces for DC distribution systems there are the voltage source converters (VSCs) with regulated input current [1], [2]. In this application the VSC provides the energy exchange with the grid according to the load request and to the availability from renewable sources (RES). In order to guarantee this performance a bi-directional current flow is necessary [3].

On the other hand, the storage systems, available on the market at reasonable costs, have opened new perspective for both islanded and grid connected plants [4]. As a matter of fact, regardless of the intermittent and unpredictable nature of RES it is possible to properly supply the load if a storage system is used [5], [6]. In particular, with a suitable storage sizing, grid connected DC systems utilizing all locally generated power and drawing power from the grid only if necessary, can be devised. In this case, the use of a PFC active rectifier as grid interface is an advantageous solution thanks to its intrinsic operation with unitary power factor and simplicity.

Irrespective of the chosen converter scheme, the power grid interface, manages a considerable amount of the system power, therefore it has to provide an efficiency as high as possible.

As for the DC distribution system, in [7] an increase of energy efficiency in the range $10-22 \%$ respect to the case of an AC distribution system is shown in buildings for any voltage level. In [8] a comparative calculation of the power losses between an AC and a DC based distribution system for a complex of 20 residential units is given, obtaining a loss reduction in the order of $15 \%$ when a $400 \mathrm{~V}$ DC system is used.

This paper aims to compare the energy losses in the GSC in two different architectures of grid connected DC distribution system for a residential unit including renewables/storage. In both cases the same amount of energy generated by RES and the load profile are considered. In the first case, an active rectifier based on an H-bridge with bi-directional current flow is adopted, whereas, in the second case, a storage system is used in association with a PFC active rectifier giving energy from the grid only when necessary. Both the systems are based on a $400 \mathrm{~V}$ DC distribution scheme.

The paper is organized as follows: in Section 2 the two electrical architectures under study are described; Section 3 explains the operation of the two topologies of GSCs used in the two studied situations; Section 4 deals with the evaluation of the reference current for both the GSCs. In Section 5 the formulation of losses in power converters is given and, finally, a comparison of losses in the two GSCs is presented in Section 6. 


\section{Electrical Schemes under Study}

The first case study is depicted in Fig. 1. In this case, the electrical architecture includes: the PV generator, the wind generator, the DC bus for power distribution in the residential unit, the loads and the H-bridge based active rectifier, used as GSC. Fig. 1 shows the possibilities for power flows, as well.

The second case study includes the same solar and wind generation units and considers the same loads as in the first case, but, in addition, it uses a PFC active rectifier for the grid connection and a storage unit based on a battery bank, as shown in Fig. 2. The possibilities for power flows using this electrical scheme are highlighted in Fig. 2 as well.

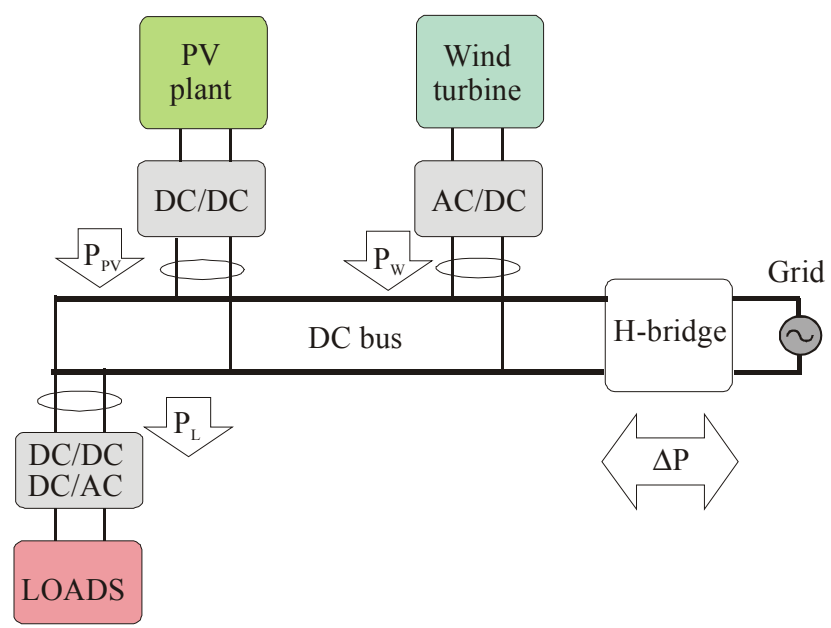

Fig. 1: Grid connected DC distribution system for a residential unit using an H-bridge active rectifier as GSC.

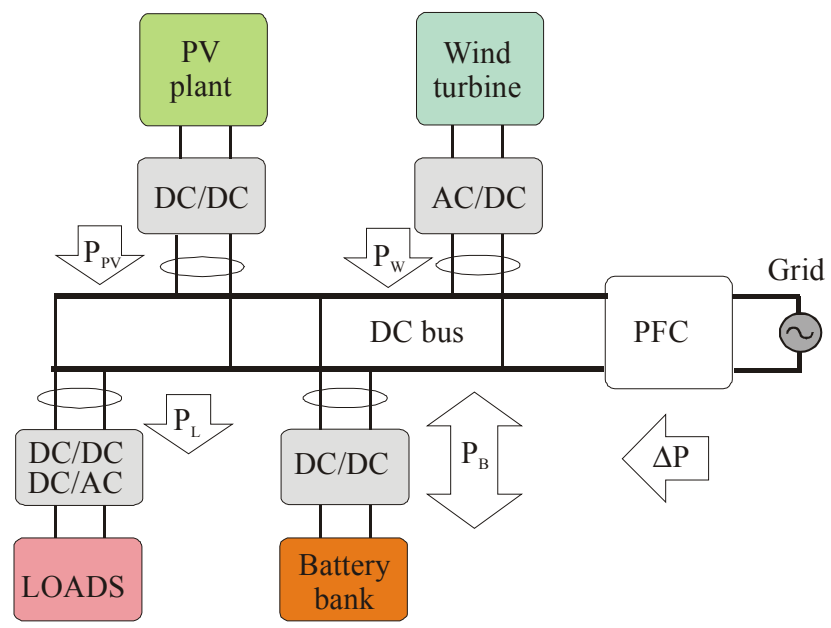

Fig. 2: Grid connected DC distribution system for a residential unit using as PFC active rectifier as GSC.

For both the considered cases, data related to one year of power generation/demand, registered in the south of Italy, have been used. In particular, as for data of generated power, the power achievable by a renewable energy generation system for a residential application composed of a $3 \mathrm{kWp}$ photovoltaic plant and a vertical axes $1 \mathrm{~kW}$ wind turbine has been measured at the output of the power inverter connection, say, at its connection to the $400 \mathrm{~V} \mathrm{DC}$ bus. In this way the measured power takes into account the conversion system efficiency.

At the same time, the overall power consumption of the residential unit has been recorded. It represents all the loads including the related power conversion units.

All data have been sampled each 15 minutes and three vector of powers containing 35040 points have been obtained. In detail, the three vectors contain, respectively, the power given by the PV plant $P_{P V}$, the power given by the wind plant $P_{\text {wind }}$, and the power required by the residential unit's loads $P_{\text {load }}$.

Fig 3 shows the plot of the three power profiles in the period of observation.
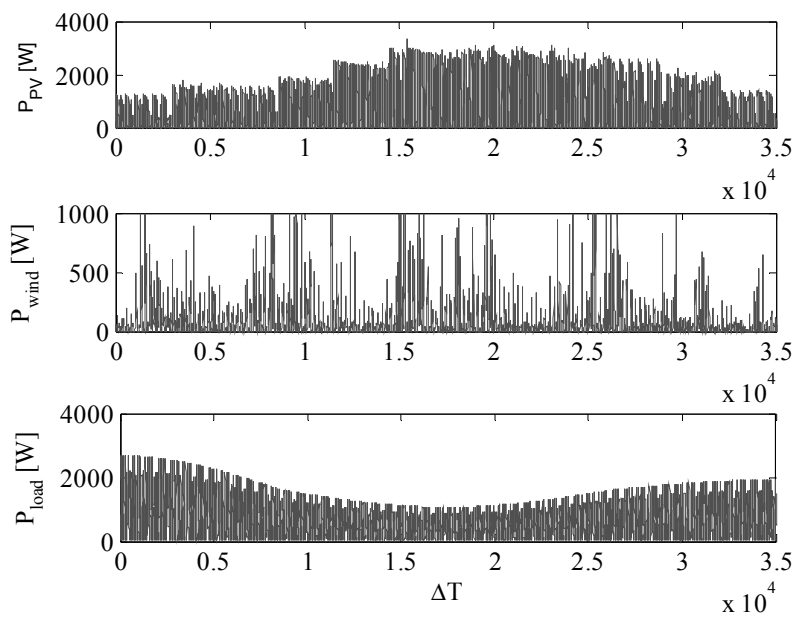

Fig. 3: Yearly power profiles: power generated by the PV generation system (top); power generated by the wind generation system (middle); power requested by the residential unit's loads (bottom).

\section{Grid Side Converters}

\section{A. H-bridge based GSC}

The active rectifier can be obtained by a voltage controlled H-bridge converter as shown in Fig 4. It can be seen that the bridge is connected via an inductance with its parasitic resistance to the grid and, on the DC side, with a load or a source.

Different solutions have been devised for grid connection of an H-bridge based active rectifier, for example by using an LC or an LCL filter. The use of a single inductance is the simplest solution as for the number of components; on the other hand, to reduce the current harmonics around the switching frequency, a high value of input inductance should be selected. This implies for applications above several $\mathrm{kW}$ a high cost and a poor system dynamic.

The operation of the H-bridge active rectifier can be explained with the aid of the representation in Fig. 5. The converter acts as a current source where the current is obtained as the difference between the generated voltage $u_{s}$, depending on the power switch states, and the grid voltage $u_{g}$ applied to the inductance $L$. The resulting current can be injected both toward the grid or to the load.

Some characteristic situations are sketched in Fig. 5 using phasor diagram. In particular, Fig. 5a shows a 
generic operating condition where the grid voltage results from the sum of inverter voltage phasor, and the phasors of the drop on inductance and the drop on the parasitic resistance. Fig. 5b represents a rectification at unity power factor. With the imposed inverter voltage, the sum of the drop on inductance and of the drop on resistance makes the current in phase with the grid voltage. The power flow goes from the grid to inverter representing the rectifier behaviour. Finally, Fig. 5c shows the inversion at unity power factor. In this last case grid voltage phasor and current phasor are in opposition. It should be borne in mind that in Fig. 5 the resistive drop has been overstated for the sake of clarity.

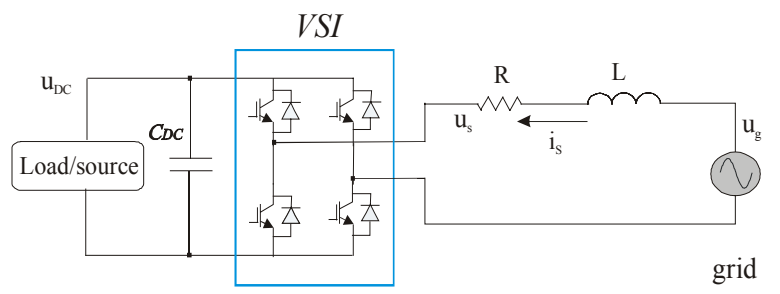

Fig. 4: H-bridge active rectifier scheme.
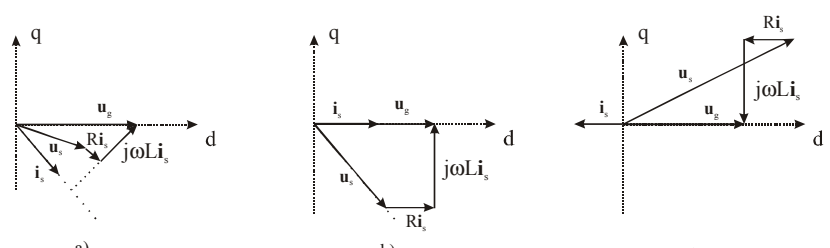

b)

Fig. 5: Representation of different operations of the H-bridge: a) generic operation; b) rectification at unitary power factor; c) inversion at unitary power factor.

\section{B. PFC based GSC}

The PFC active rectifier is basically a diode bridge rectifier followed by a DC/DC converter. When connected to the grid, the DC/DC converter control forces the grid current to have the same shape as the grid voltage and to be in phase with it, so that a resistive equivalent input impedance is obtained. For this reason this converter is called by some authors resistor emulator [12]. If supplied by a single phase AC line at $230 \mathrm{~V}-50 \mathrm{~Hz}$, a boost-based scheme is needed for the DC/DC stage to obtain the desired $400 \mathrm{~V}$ DC.

The effective or emulated resistance $R_{e}$ of the PFC converter is defined as the constant of proportionality between the grid current and the input voltage; its value can be obtained by:

$R_{e}=V_{M}^{2} / 2 P$

where $V_{M}$ is the maximum value of the grid voltage.

The condition of CCM is verified if

$R_{e}<2 L / T_{s}$

where $L$ is the boost filter's inductance and $T_{s}=1 / f_{s}$ is the switching period [10].

With reference to the control design, an indirect current control scheme is adopted whose main advantage is that it does not need the measurement of the input voltage and the use of a multiplier for its implementation. It is based on the following control law:

$$
R_{S} i_{s, a v g}=v_{m} / M(d)
$$

where $R_{s}$ is the current sensing resistance, $i_{s, a v g}$ is the average value of diode bridge output current, $v_{m}$ is the control voltage and $M(d)$ is the voltage conversion ratio of the DC/DC converter. For the boost-based topology the average value of the input current coincides with the average value of the inductor current, whereas $M(d)=$ $1 /(1-d)$.

The PFC rectifier scheme, including its control, is shown in Fig. 6 [13].

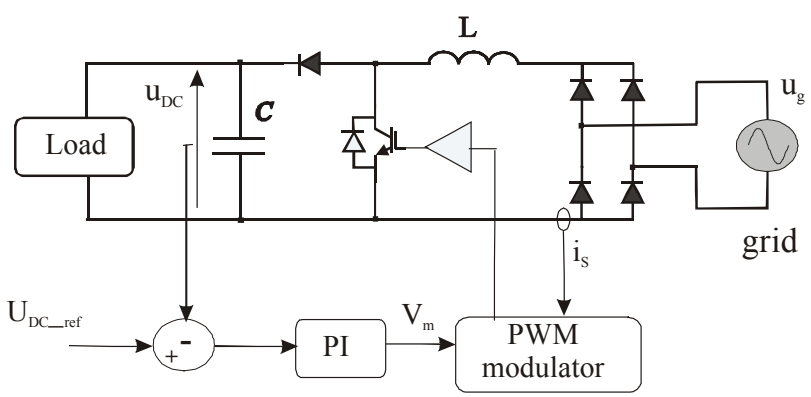

Fig. 6: PFC boost active rectifier scheme.

\section{GSCs Reference Current Determination}

In order to evaluate the energy efficiency of the GSCs described in the previous Section, the current stresses on the converters devices have to be determined. These currents can be deduced by the currents delivered to (or withdrawn by) the DC grid in the two cases.

For the case with the H-bridge active rectifier used as power grid interface, where no storage system is present, the current reference of the GSC on the DC side is obtained as:

$i_{\text {ref_A }}=\left[P_{L}-\left(P_{P V}+P_{\text {wind }}\right)\right] / V_{D C}$

where $V_{D C}$ is the DC bus voltage equal to $400 \mathrm{~V}$.

The current reference value obtained by (4) can be either negative (from the DC bus toward the grid) or positive (from the grid toward the DC bus), depending on whether the renewable sources are able to supply the load request or not.

For the case with the PFC used as power grid interface, the battery bank aims to reduce the power demand to the grid. In this case, when the power generated by renewables is higher than that needed by the load, the batteries are charged. On the contrary, when the stored energy in the batteries is lower than a minimum corresponding to the overdischarging, the grid supplies the load. It should be observed that, in case the charge of the batteries reaches the maximum value, the charging process is stopped. Current flow towards the grid is never possible, as shown in Fig. 2. 
The battery capacity is defined on the basis of the amount of energy that can be extracted from it; therefore, during the charge, the efficiency is assumed equal to the roundtrip efficiency and during the discharge is assumed as unitary [9]. It should be noted that in this analysis the battery self-discharging rate is neglected.

If the energy generated by renewables exceeds the load demand, the batteries are charged and the stored energy at the time $k \Delta t$ is equal to:

$$
E_{B_{-}(k)}=E_{B_{-}(k-1)}+\eta_{\text {batt_in }}\left(\frac{P_{P V}+P_{\text {wind }}-P_{L}}{\eta_{\text {batt_conv }}}\right) \Delta t
$$

where

$\eta_{\text {battconv }}$ is the efficiency of the DC/DC converter interfacing the batteries with the DC bus;

$\eta_{\text {batt_in }}$ is the round-trip efficiency;

$k$ is the number of sample;

$\Delta t$ is the sampling time.

When the load demand is greater that the energy given by renewables, the batteries are discharged and the released energy at the time $k \Delta t$ is given by:

$$
E_{B \_(k)}=E_{B \_(k-1)}+\left(\frac{P_{P V}+P_{\text {wind }}-P_{L}}{\eta_{\text {batt_conv }}}\right) \Delta t
$$

The energy stored, calculated each sampling time, is subject to the constraints:

$$
E_{B_{-} \min } \leq E_{B_{-}(k)} \leq E_{\text {max }}
$$

Then, assuming $P_{L}-\left(P_{P V}+P_{\text {wind }}\right)=\Delta P$, the reference current of the PFC active rectifier is given by:

$i_{\text {ref_PFC }}=\left\{\begin{array}{cc}\frac{\Delta P}{V_{D C}} & \text { for } \Delta P>0 \text { and } E_{B_{-}(k)}=E_{B_{-} \text {min }} \\ 0 \text { otherwise }\end{array}\right.$

The reference is always positive, that implies a unidirectional power flow from the grid towards the load, as expected.

\section{Losses in power converters}

The power losses in power converters are defined once the contributions due to their individual components are evaluated. In general the following contributions are considered: power losses of the power switches (in this case IGBTs); power losses of the free-wheeling diodes; power losses on the inductor copper; power losses on the inductor magnetic core; joule losses on the connection wire resistance and leakage losses.

The power losses on both the power switch and the freewheeling diode can be expressed by the sum of three terms, i.e., the conduction losses, the switching losses and the capacitive losses, according to (9) and (10):

$$
\begin{aligned}
& P_{S}=P_{c S}+P_{s w S}+P_{c a p S} \\
& P_{D}=P_{c D}+P_{s w D}+P_{c a p D}
\end{aligned}
$$

where the terms $P_{c}$ represent the conduction losses, the terms $P_{s w}$ represent the switching losses and $P_{c a p}$ represent the capacitive losses, respectively. The subscripts $S$ and $D$ refer respectively to the power switch and the freewheeling diode.

Detailing the individual losses terms in (9) the following expressions are obtained [10], [11]:

$$
\begin{aligned}
& P_{c S}=u_{C E 0} I_{S_{-} a v}+R_{S_{-} o n} I_{S_{-} r m s}^{2} \\
& P_{s w S}=\left[E_{\text {onS }}+E_{\text {off } S}\right] / T_{S} \\
& P_{c a p S}=\frac{1}{2 T_{S}} C_{S} V_{o f f}^{2}
\end{aligned}
$$

where $R_{S_{-} \text {on }}$ is the on-state resistance of the power switch, $u_{C E O}$ is collector to emitter saturation voltage, $I_{S_{-}}$is the switch current, $V_{\text {off }}$ is the switch maximum output voltage in OFF state, $E_{\text {ons }}$ and $E_{\text {offS }}$ are the switch on and switch off energy of the power switch, $T_{s}$ is the switching period and, finally, $C_{S}$ is the switch internal capacitance.

Detailing the individual terms in (10) the following expressions are obtained for the diode:

$$
\begin{aligned}
& P_{c D}=u_{D 0} I_{D_{-} a v}+R_{D} I_{D_{-} r m s} \\
& P_{s w D} \cong E_{o n D} f_{s w}=\frac{1}{4 T_{s}} Q_{D r r} V_{D r} \\
& P_{c a p D}=\frac{1}{2 T_{s}} C_{D} V_{D r}^{2}
\end{aligned}
$$

As for the symbols used in (14), (15) and (16), $u_{D 0}$ is the diode forward voltage, $I_{D}$ is the diode current, $E_{\text {onD }}$ is the switch-on energy of the diode (practically coinciding with the reverse recovery energy), $Q_{D r}$ is the diode reverse recovery charge, $C_{D}$ is the capacitance of the diode and $V_{D r}$ is the voltage across the diode during reverse recovery.

As for the joule losses on the parasitic resistance of the inductor, they are expressed as:

$$
P_{r_{L}}=r_{L} I_{L}^{2}
$$

where $I_{L}$ is the average value of the inductor current and $r_{L}$ is the inductor parasitic resistance.

Other power losses contributions, such as power losses on the inductor magnetic core, joule losses on the connection wire resistance and leakage losses have a small influence on the converter efficiency and can be neglected.

On the basis of the losses expressions defined in (11)(17), the energy lost in the GSC in both the studied configurations is determined. 


\section{Losses Comparison in GSCs}

In order to compare the efficiency of the two considered GSCs, the following components have been adopted for the converters set up:

- Power switch: FGH20N60UFD, operated at the switching frequency: $f_{s}=50 \mathrm{kHz}$, whose parameters are given in Table I;

- Power diode: STTH3006, whose parameters are given in Table I;

- Inductor of $2 \mathrm{mH}$ with parasitic resistance of $0.3 \Omega$.

Since both converters are thought as input conversion stages of a single residential unit, a rated power $P=3 \mathrm{~kW}$ is chosen.

Table I

Parameters of the power switch and the power diode

\begin{tabular}{|c|c|}
\hline \multicolumn{2}{|c|}{ Power switch FGH20N60UFD } \\
\hline$\tau_{r}$ & $16 \mathrm{~ns}$ \\
\hline$\tau_{f}$ & $63 \mathrm{~ns}$ \\
\hline$V_{c e(s a t)}$ & $1.8-2.4 \mathrm{~V}$ \\
\hline$C_{S}$ & $110 \mathrm{pF}$ \\
\hline \multicolumn{2}{|c|}{ Power diode STTH3006 } \\
\hline$V_{D f}$ & $1.1-1.4 \mathrm{~V}$ \\
\hline$Q_{D r r}$ & $1-2.5 \mu \mathrm{C}$ \\
\hline$C_{D}$ & $50 \mathrm{pF}$ \\
\hline
\end{tabular}

Moreover, as for the power diode, the manufacturer gives the following formula to calculate the conduction losses:

$$
P_{c D}=1.07 I_{D_{0} n_{-} a v}+0.011 I_{\text {Don_rms }}^{2}
$$

The energy required to the grid by the load without any RES contribution is shown in Fig. 7 where the abscissa values correspond to the $\mathrm{n}$-th sample taken every $15 \mathrm{~min}$. It should be noted that the curve exhibits a lower slope in correspondence of the summer months as expected. At the end of the year the load would require $6128 \mathrm{kWh}$.

Considering now the support of the RES, the energy exchanged with the power grid, in the case of the Hbridge used as GSC (bi-directional power flow), has been evaluated. The corresponding curves are shown in Fig. 8. The final values at the end of the year for the energy demanded to the grid and for the energy delivered to the grid are equal to $3380 \mathrm{kWh}$ and to $2450 \mathrm{kWh}$, respectively. Moreover, the energy demand to the grid in the case of using a PFC as GSC (in association with a storage system), is calculated for different sizing of the storage system assuming $\eta_{\text {batt_conv }}=0.965$ and $\eta_{\text {batt in }}=0.93$. The energy demand curves are plotted in Fig. 9. The final values at the end of the year for the energy demanded to the grid are equal to $643 \mathrm{kWh}$ for a storage system with capacity of $1000 \mathrm{kWh}$, to $1368 \mathrm{kWh}$ for a storage system with capacity of $500 \mathrm{kWh}$, and to $1733 \mathrm{kWh}$ for a storage system with capacity of $250 \mathrm{kWh}$.

Finally, the energy lost in the period of observation, for the two GSCs, has been determined. In particular, the energy lost in the H-bridge is shown in Fig. 10, whereas the energy lost in the PFC, for different storage sizing, is sketched in Fig. 11.

As for the H-bridge, it is worth noting that, at the end of the year of observation, a value of lost energy of $192 \mathrm{kWh}$ has been found.On the other hand, the PFC exhibits lower losses equal to $11.6 \mathrm{kWh}$ for a storage system with capacity of $1000 \mathrm{kWh}$, to $25.2 \mathrm{kWh}$ for a storage system with capacity of $500 \mathrm{kWh}$, and to $32 \mathrm{kWh}$ for a storage system with capacity of $250 \mathrm{kWh}$. As expected, the higher is the storage size, the lower will be the energy lost in the PFC. All results are summarized in Table II

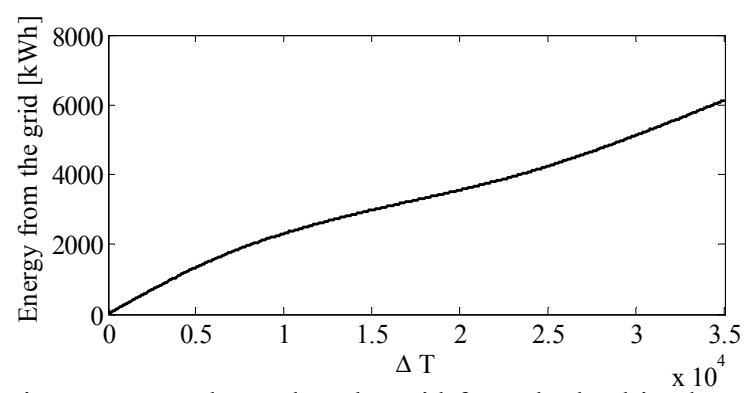

Fig. 7. Energy demand to the grid from the load in absence of RES
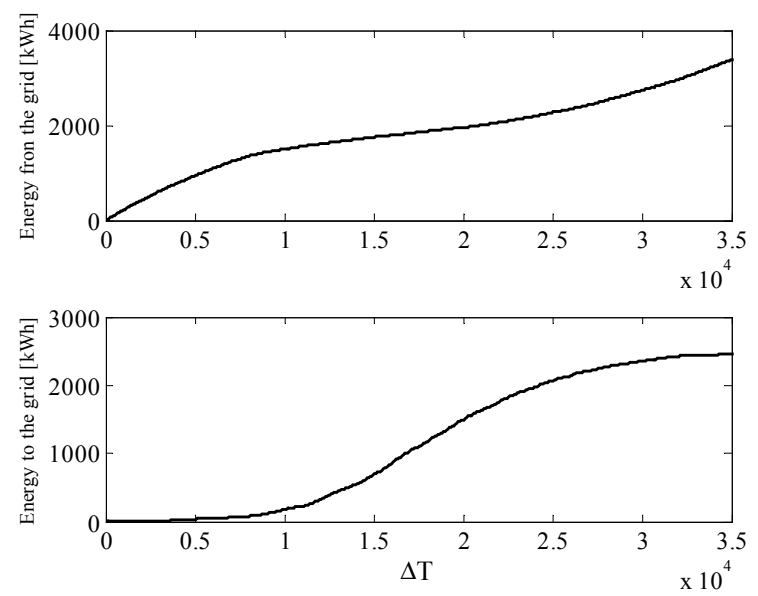

Fig. 8. Energy demand to the grid (top) and energy delivered to the grid (bottom) in the case of H-bridge used as GSC.

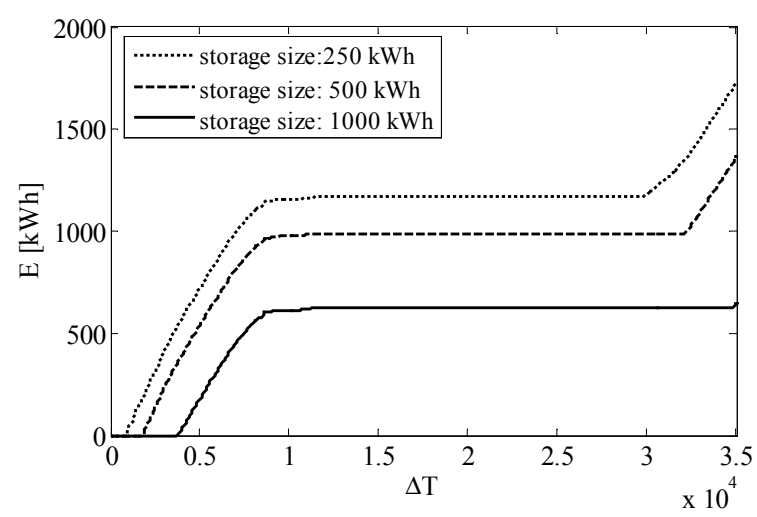

Fig. 9. Energy demand to the power grid for different storage sizing in the case of PFC used as GSC.

Finally, the energy lost in the storage system has been calculated by the following formula:

$E_{B_{-} \text {lost }(k)}=E_{B_{-} \text {lost }(k-1)}+\left(1-\eta_{\text {batt_in }}\right)\left(\frac{P_{P V}+P_{\text {wind }}-P_{L}}{\eta_{\text {batt_conv }}}\right) \Delta t$ 
with the constraint (7), for which energy is lost only when the battery is charged. The obtained values at the end of the year are summarized in Table III.

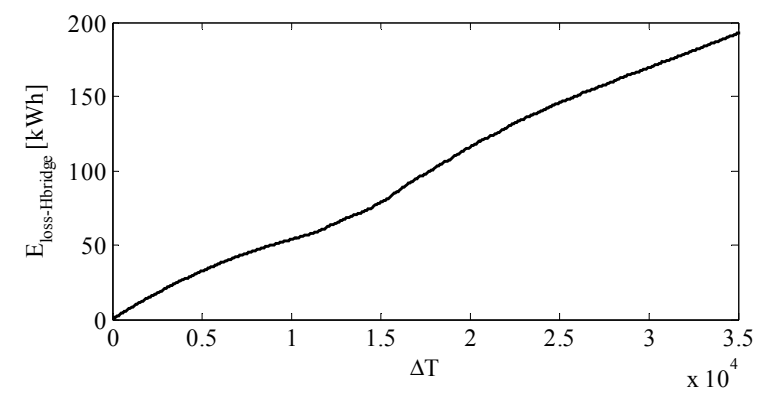

Fig. 10. Energy lost in the H-bridge.

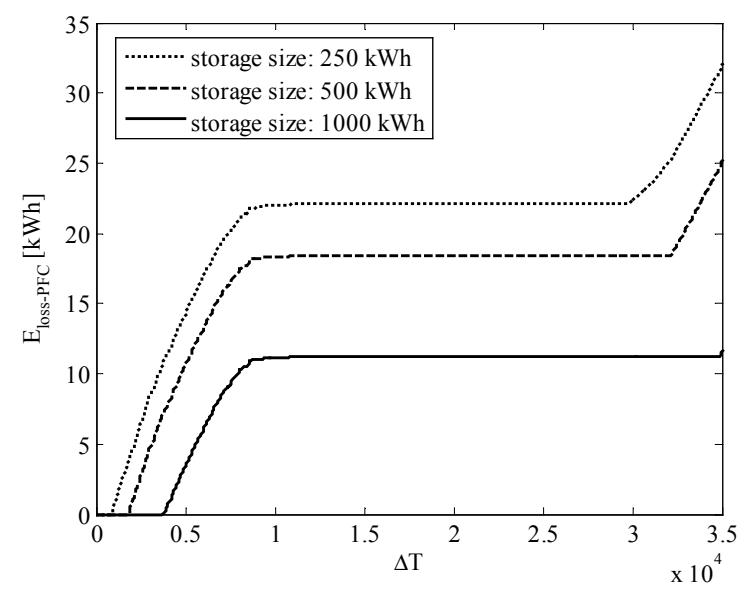

Fig. 11. Energy lost in the PFC for different storage sizing.

Table II

Main values of energy at the end of the year of observation

\begin{tabular}{|l|l|l|l|l|}
\hline \multicolumn{2}{|l|}{} & $\begin{array}{l}\text { demanded } \\
\text { Energy }\end{array}$ & $\begin{array}{l}\text { lost } \\
\text { Energy }\end{array}$ & $\begin{array}{l}\text { delivered } \\
\text { Energy }\end{array}$ \\
\hline H-bridge & $3380 \mathrm{kWh}$ & $192 \mathrm{kWh}$ & $2450 \mathrm{kWh}$ \\
\hline \multirow{2}{*}{$\begin{array}{l}\text { PFC } \\
\text { with } \\
\text { storage }\end{array}$} & $1000 \mathrm{kWh}$ & $654 \mathrm{kWh}$ & $11.6 \mathrm{kWh}$ & - \\
\cline { 2 - 5 } & $500 \mathrm{kWh}$ & $1393 \mathrm{kWh}$ & $25.2 \mathrm{kWh}$ & - \\
\cline { 2 - 6 } & $250 \mathrm{kWh}$ & $1765 \mathrm{kWh}$ & $32.0 \mathrm{kWh}$ & - \\
\hline
\end{tabular}

Table III

Energy lost in the storage system at the end of the year of observation

\begin{tabular}{|c|c|}
\hline Storage size $[\mathrm{kWh}]$ & Lost Energy $[\mathrm{kWh}]$ \\
\hline 1000 & 162 \\
\hline 500 & 131 \\
\hline 250 & 116 \\
\hline
\end{tabular}

\section{Conclusions}

This paper proposes a comparison of energy lost during operation in two different power converters used as GSC. Two architectures of grid connected DC distribution system for a residential unit, including renewables/storage, have been considered. One scheme uses an H-bridge active rectifier as GSC and the other uses a PFC active rectifier. The first solution is more flexible since it allows a bidirectional power flow for which the exceeding energy can be sold to the grid manager. On the other hand, in absence of RES the load can be supplied only by the grid. Finally, the converter is always operating and employs four power devices, then it exhibits greater power losses.
The second solution allows a unidirectional power flow and can be properly used if a storage system is included. The converter energy losses are lower due to both its simpler topology and to the operation of the storage system. In particular, the intervention of the storage system ensures that the converter is not running for some periods and that the load can be supplied in absence of RES for a time interval depending on the storage size.

On the other hand, an initial investment is required to buy the storage system.

Actually, the solution with PCF can become more competitive with cheaper and lower losses storage solutions.

\section{References}

[1] R. A. Mastromauro, M. Liserre, A. Dell'Aquila, "Control Issues in Single-Stage Photovoltaic Systems: MPPT, Current and Voltage Control", IEEE trans. on Ind. Informatics, vol. 8, n. 2, May 2012, pp 241-254.

[2] B. Bahrani, A. Rufer, S. Kenzelmann, L. A. C. Lopes, "Vector Control of Single-Phase Voltage-Source Converters Based on Fictive-Axis Emulation", IEEE trans. on Ind. Appl. vol. 47, March/April 2011.

[3] M. Cirrincione, M. Pucci, G. Vitale, "Power Converters and AC Electrical Drives with Linear Neural Networks", CRC press, Boca Raton, Fl, USA, 2012.

[4] G. Coppez, S. Chowdlury, S. P. Chowdlury, "Review of Battery Storage Optimisation in Distributed Generation", in Proc. Joint International Conference on Power Electronics, Drives and Energy Systems (PEDES) \& 2010 Power India, 2010, pp. 1-6.

[5] A. Rajendra Prasad, E. Natarajan, "Optimization of integrated photovoltaic-wind power generation systems with battery storage", Energy, 31 (2006) 1943-1954.

[6] W. Zhou C. Lou, Z. Li, L. Lu, H. Yang, "Current status of research on optimum sizing of stand-alone hybrid solar-wind power generation systems", Applied Energy 87 (2010) 380 389.

[7] S. Anand, B. G. Fernandez, "Optimal voltage level for DC microgrids", in Proc. $36^{\text {th }}$ Annual Conference on IEEE Industrial Electronics Society (IECON 2010), 2010, pp 30343039.

[8] H. Kakigano, N. Nomura, T. Ise, "Loss evaluation of DC distribution for resisdential houses compared with AC system", in Proc. 2010 International Power Electronics Conference (IPEC), 2010, pp 480-486.

[9] B. S. Borowy, Z. M Salameh, "Methodology for optimally Sizing the Combination of a Battery Bank and a PV array in a Wind/PV Hybrid System", IEEE trans on Energy Conv. vol 11, n. 2, June 1996.

[10] R. W. Erickson, D. Maksimovic, "Fundamentals of Power Electronics", Springer, USA, 2001, second edition.

[11] D. Graovac, M. Purschel, A. Kiep, "Mosfet power losses calculation using the data sheet parameters", Infineon Application Note, V 1.1, July 2006.

[12] Z. Lai Keyue, K. M. Smedley "A Family of ContinuousConduction-Mode Power-Factor-Correction Controllers Based on the General Pulse-Width Modulator", IEEE Trans. on Power Electron., vol. 13, n.3, May 1998.

[13] A. Amirahmadi, A. Dastfan, S. M. R. Rafiei, "Design of a PFC rectifier with fast start up response and low input current distortion", International Conference on Renewable Energies and Power Quality (ICREPQ'10), Granada (Spain), 23-25 March, 2010. 